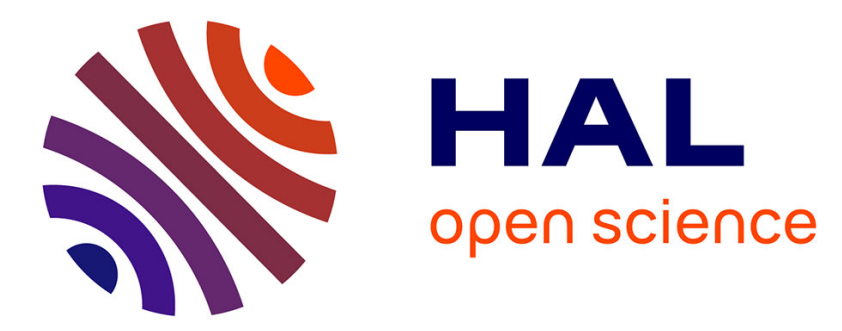

\title{
Pseudopolarography of lead (II) in sediment and in interstitial water measured with a solid microelectrode
}

Ivanka Pižeta, Gabriel Billon, Dario Omanovic, Vlado Cuculic, Cédric

Garnier, Jean-Claude Fischer

\section{- To cite this version:}

Ivanka Pižeta, Gabriel Billon, Dario Omanovic, Vlado Cuculic, Cédric Garnier, et al.. Pseudopolarography of lead (II) in sediment and in interstitial water measured with a solid microelectrode. Analytica Chimica Acta, 2005, 551, pp.65 - 72. 10.1016/j.aca.2005.07.009 . hal-01096807

\section{HAL Id: hal-01096807 \\ https://hal-univ-tln.archives-ouvertes.fr/hal-01096807}

Submitted on 5 Jan 2015

HAL is a multi-disciplinary open access archive for the deposit and dissemination of scientific research documents, whether they are published or not. The documents may come from teaching and research institutions in France or abroad, or from public or private research centers.
L'archive ouverte pluridisciplinaire HAL, est destinée au dépôt et à la diffusion de documents scientifiques de niveau recherche, publiés ou non, émanant des établissements d'enseignement et de recherche français ou étrangers, des laboratoires publics ou privés. 


\title{
Pseudopolarography of lead (II) in sediment and in interstitial water measured with a solid microelectrode
}

\author{
Ivanka Pižeta $^{\mathrm{a}, *}$, Gabriel Billon ${ }^{\mathrm{b}}$, Dario Omanovića ${ }^{\mathrm{a}}$, Vlado Cuculića ${ }^{\mathrm{a}}$, \\ Cédric Garnier $^{\mathrm{b}}$, Jean-Claude Fischer ${ }^{\mathrm{b}}$ \\ ${ }^{a}$ Center for Marine and Environmental Research, Ruđer Bošković Institute, P.O. Box 180, Bijenička c. 54, 10002 Zagreb, Croatia \\ ${ }^{\mathrm{b}}$ Université des Sciences et Technologies de Lille 1, Laboratoire de Chimie Analytique et Marine, \\ Bât C8, 59655 Villeneuve d'Ascq Cedex, UMR CNRS 8013, France
}

Received 18 March 2005; received in revised form 1 July 2005; accepted 13 July 2005

Available online 22 August 2005

\begin{abstract}
Pseudopolarograms of lead (II) constructed from the voltammograms measured in situ in the sediment and in the interstitial water by using an Ir solid microelectrode with a thin mercury film have shown as a kind of fingerprints of the sample. Despite shortcomings when compared to measurements with the mercury drop electrode and in model solutions, the measurement procedure was adapted for enough signal repeatability, avoiding to a reasonable extent the memory effect and electrode surface blocking. To make the best use of the information available, besides the classical pseudopolarograms, i.e. besides the dependence of the peak-height on the deposition potential, it is necessary to analyze the peak-area, the peak-position and the half-peak width versus deposition potential, and combine them with the knowledge from various theoretical and model situations. They have shown to contain interesting information about speciation. This information is not always unambiguous, it is often semi-quantitative, and cannot be reached by other methods, however, in combination with other methods it could be useful for the characterization of the sample solution. Pseudopolarograms of lead (II) in different liquid fractions of the sediment were measured and compared, the electrode sensitivity varying from 4 to $20 \mathrm{nA} / \mu \mathrm{mol} \mathrm{L}^{-1}$ of lead (II). The differences in half-wave potentials recorded were ranging up to $0.6 \mathrm{~V}$ and those in the slopes of pseudopolarograms were three-fold, having interesting relationships with the peak potentials of single voltammetric curves.
\end{abstract}

(C) 2005 Elsevier B.V. All rights reserved.

Keywords: Pseudopolarography; Ir solid microelectrode; Sediment; Interstitial water; Speciation; Lead (II)

\section{Introduction}

Pseudopolarography is a method appropriate for distinguishing the labile from the inert complexes of dissolved trace metals with ligands in their natural concentrations [1-29]. It can be particularly applied for the speciation of trace metals that form amalgams, being based on anodic stripping voltammetry or lately on stripping chronopotentiometry as

\footnotetext{
* Corresponding author. Tel.: +385 14561 190; fax: +38514680 231 .

E-mail addresses: pizeta@irb.hr (I.Pižeta),gabriel.billon@univ-lille1.fr (G. Billon), omanovic@irb.hr (D. Omanović), cuculic@irb.hr (V. Cuculić), cgarnier@univ-tln.fr (C. Garnier), jean-claude.fischer@univ-lille1.fr (J.-C. Fischer).
}

well [30-33]. A pseudopolarogram, which is similar in shape to the classical polarogram, is the dependence of peak-heights of a redox reaction on the deposition potential, which changes in subsequent voltammetric measurement cycles $[1,3,4,7,8]$, and which reflects thermodynamic and kinetic properties of metal ions as well as geometric and hydrodynamic characteristics of the working electrode. The main parameters used for the speciation of trace metals using pseudopolarographic data are the half-wave potential and the limiting current. However, we can benefit from the entire shape of the pseudopolarographic curve, which provides a scanning image (fingerprint) of the investigated electrochemical reactions. It was shown that thermodynamic stability constant of the inert metal complex can be obtained from the difference between the standard 
potentials of the redox reactions of the free and of the inert complexed metals [10]. This theoretical concept is empirically used for the determination of stability constants of inert metal complexes using pseudopolarographic half-wave potentials, and is successfully applied for trace metals speciation of unknown natural aquatic systems $[18,19,28,29]$. From the ratio of the limiting currents of the labile and inert metal complexes (using known side reaction data) the calculation of the stability constant is possible, as well. The parameters relative to the redox reaction, such as the transfer coefficient and the rate constant, can be obtained through the analysis of the shape of pseudopolarographic wave $[34,35]$.

Theoretical background for the pseudopolarography has been developed for the hanging mercury drop electrode [4,7], for the thin film electrode under different conditions $[8,11,36]$ and for the mercury ultramicroelectrode [9]. The automation of the pseudopolarographic measurement is crucial for its wider employment and has been achieved with the nowadays instrumentation and the existing software [23].

There is often a considerable discrepancy when measuring and examining model solutions with well-defined composition and the measuring of the samples of natural, polluted or pore waters. This is truth already when the working electrode is a mercury hanging drop electrode, with the surface renewed for every cycle of the measurement, but if instead, the working electrode is a solid electrode, more problems could be encountered, something to be worried about. In that case it cannot be counted on single "clear" effects, one by one thoroughly elaborated in the literature, to appear one at a time, instead a superposition of various effects should be expected. Anyhow, voltammetric in situ measurements are restricted to the solid electrodes that can be moved vertically to characterize depth profiles, or they can follow the evolution in time of a single sampling site either by simple repeating of measurements or by gradually changing one of the parameters of the method as in the case of pseudopolarography.

Lead is a toxic, nonessential element, thus its increased concentrations in the media affect living organisms inducing negative physiological effects [37]. During the early diagenetic processes, iron oxides were reduced, which lead to releasing $\mathrm{Pb}^{2+}$ into pore waters, while the production of sulphides tended to (co)precipitation of $\mathrm{Pb}^{2+}$ (mainly as $\mathrm{PbS}$ or $\mathrm{Pb}$ associated with $\mathrm{FeS}_{2}$ ) [38,39]. Nevertheless, partial redissolution might occur at the oxic-anoxic interfaces [40,41,38], especially when the concentration of lead in high contaminated sediments reaches nearly $1 \mathrm{~g} \mathrm{~kg}^{-1}$. Moreover, significant enrichment of trace elements in interstitial waters has been explained by the effect of complexing by organic substances [42]. This explains why the concentrations of most of the trace elements in interstitial waters were significantly higher than could have been predicted from their sulphide solubility $[38,43]$. On the other hand, lead is a classical element to be investigated by voltammetry and a mercury drop as a working electrode as it forms amalgams, and even a large number of pseudopolarographic measurements were made in model and natural solutions with lead as the analyte [3,8,10,12,21,24,27,29-31,34].

Pseudopolarograms obtained in the experiments described in this work differ from the theoretical assumptions and calculations, or at least they represent a combination of several ones. Shifts of half-wave potentials and changes in the slope due to the complexation, changes in reversibility and metal-ligand ratios have been elaborated theoretically [7-11,30,32,36], as well as the existence and the effects of the combinations of electrode reactions (E) with coupled homogeneous chemical reactions (C), such as the CEC preceding and following reactions [44].

Since pseudopolarography is here considered as a kind of fingerprint of the measured sample, or the place near the electrode put in situ, retrieving more complex information from this composite voltammetric method by tracing not only the peak-height and the peak-area, but also the peak-potential and the half-peak width versus deposition potential is proposed.

\section{Experimental}

\subsection{Electrode preparation}

The experiments were performed with an Ir microelectrode, designed as described elsewhere [45] for the similar $\mathrm{Au}$ and $\mathrm{Ag}$ microelectrodes. This electrode was $75 \mu \mathrm{m}$ in diameter and the procedure of surface activation differed from the previous works in the part related to the application of mercury. Mercury was applied electrochemically from a $0.01 \mathrm{M}$ solution of $\mathrm{Hg}\left(\mathrm{NO}_{3}\right)_{2}$ at $-0.4 \mathrm{~V}$ versus $\mathrm{Ag} / \mathrm{AgCl}$, $[\mathrm{KCl}]=3 \mathrm{~mol} \mathrm{~L}^{-1}$. A very thin film of mercury was deposited in order to avoid memory effect, which was observed with a hemispheric mercury drop. Under the microscope neither the mercury layer nor the mercury drops were observed. Kept in distilled water, the electrode was stable for several days. The sensitivity of the electrode was checked by the standard addition method with lead (II) and cadmium (II), before and after the experiments.

\subsection{Instrument and chemicals}

A $\mu$ Autolab 2, multimode polarograph with the software package GPES 4.8 (Ecochemie, Utrecht) was used. A Metrohm Stand 663 was used for mercury deposit and calibration steps, where a facility for proper purging with nitrogen was needed. Purging with nitrogen was also applied when measuring the interstitial water samples in order to prevent any oxidation of the medium. Stirring the solution was not applied in order to approach in situ conditions, cell volume was $20 \mathrm{ml}$, and supporting electrolyte for calibration measurements was filtered seawater of 31 salinity. The reference electrode was an $\mathrm{Ag} / \mathrm{AgCl}$ electrode and the counter electrode was a Pt wire. The reference electrode for in situ measurement was a Unisense $\mathrm{Ag} / \mathrm{AgCl}$ electrode and the counter electrode was a robust Pt rod electrode. The applied methods were 
square wave voltammetry (SWV) for measuring, and cyclic voltammetry $(\mathrm{CV})$ for stabilizing and cleaning the electrode [45]. All the potentials were measured versus $\mathrm{Ag} / \mathrm{AgCl}$. If not stated otherwise the following conditions were applied: for SWV - conditioning potential $E_{\text {cond }}=-0.1 \mathrm{~V}$, conditioning time $t_{\text {cond }}=60 \mathrm{~s}$, deposition potential $E_{\text {dep }}$ from -1.3 to $-0.9 \mathrm{~V}$ or to $-0.32 \mathrm{~V}$, deposition time $t_{\mathrm{dep}}=60 \mathrm{~s}$, equilibration time $t_{\mathrm{eq}}=5 \mathrm{~s}$, frequency $f=50 \mathrm{~Hz}$, step potential st $_{\text {pot }}=0.00195 \mathrm{~V}, \mathrm{SW}$ amplitude $A=0.025 \mathrm{~V}$, initial potential $E_{\text {init }}$ was $-1.3 \mathrm{~V}$ or $-0.9 \mathrm{~V}$, final potential $E_{\text {final }}=-0.1 \mathrm{~V}$; for $\mathrm{CV}$ - start potential $-1.8 \mathrm{~V}$, first vertex potential $-0.1 \mathrm{~V}$, second vertex potential $-1.8 \mathrm{~V}$, step potential $0.00198 \mathrm{~V}$, scan rate $1 \mathrm{~V} / \mathrm{s}$, number of scans 20 .

The following chemicals were used during the experiments: $\mathrm{Hg}\left(\mathrm{NO}_{3}\right)_{2} \cdot \mathrm{H}_{2} \mathrm{O}$, Merck p.a.; $\mathrm{PbCl}_{2}$ standard, Merck Titrisol; $\mathrm{HNO}_{3}$, Merck s.p. Ultrapure water was generated using Milli-(Q) Plusfilter apparatus (Millipore).

\subsection{Sample preparation}

The site where sediment and water used in this experiment were sampled is located in the River Deûle canal, near the town of Dourge (Northern France), approximately $2.5 \mathrm{~km}$ downstream from a former lead and zinc smelter, closed recently in 2003. This area is highly polluted and metal composition of the water and sediment was detailed in a previous work, published recently [46].

About $10 \mathrm{~kg}$ of sediment was collected with a Van Veen grab and put in a plastic bag. In the laboratory, the sediment sample was homogenized, put in a plastic box and left for 1 month at room temperature to achieve a new equilibrium. In addition, River Deûle canal water was also sampled at the same time and added on the surface of the sediment to prevent any drying process. After this rest period, quasi in situ measurements have been undertaken at $2 \mathrm{~cm}$ depth under the water-sediment interface. Interstitial water was afterwards sampled at this depth as follows: small perpex tubes were introduced in the sediment and the cores were put in a glove box flushed with nitrogen to avoid any oxidation of anoxic sediment. The core slices between the depth of 1.5 and $2.5 \mathrm{~cm}$ were put in polycarbonate flasks under nitrogen, centrifuged at $3000 \mathrm{rpm}$, and the overlaying fluids were recovered carefully. For some experiments, pore waters were afterwards filtered on a $0.45 \mu \mathrm{m}$ membrane filter (Alltech, cellulose acetate). These samples were introduced with a syringe in the purged voltammetric cell, previously set on the Metrohm stand, and used without any other pretreatment.

\section{Results and discussion}

The progress in the Ir solid microelectrode surface preparation, and the differences compared to our previous results on silver and gold microelectrodes [45], as well as the adjustment of voltammetric parameters for pseudopolarographic measurement in situ and in interstitial water samples, were tested and checked on natural samples. The electrode sensitivity varied between 4 and $20 \mathrm{nA} / \mu \mathrm{mol} \mathrm{L}{ }^{-1}$, and its detection limit was about $3 \times 10^{-8} \mathrm{~mol} \mathrm{~L}^{-1}$.

Four different systems were measured: filtered interstitial water with added lead (II), non-filtered interstitial water without the addition and with the addition of lead (II) ions and sediments, respectively. In each case a set of anodic stripping square wave voltammograms was recorded, necessary for the construction of a pseudopolarogram. The results will be presented with the emphasis on three main relationships: the peak-height $\left(i_{\mathrm{p}}\right)$ (or the peak-area $\left.\left(A_{\mathrm{p}}\right)\right)$, the peak-potential $\left(E_{\mathrm{p}}\right)$ and the half- peak width $\left(w_{1 / 2}\right)$ versus the deposition potential $\left(E_{\mathrm{dep}}\right)$.

\subsection{Filtered interstitial water sample - testing of the electrode}

Filtered interstitial water was used as a matrix for testing the electrode for the stability in pseudopolarographic type of measurements. At its natural $\mathrm{pH}$ of 8.6 or at the $\mathrm{pH}$ of 2.13 , obtained with the addition of $\mathrm{HNO}_{3}$, no reactant could be found. Subsequently, the concentration of $5 \times 10^{-6} \mathrm{~mol} \mathrm{~L}^{-1}$ of lead (II) ions was added to ensure a signal large enough to test the electrode. Under the project mode of GPES 4.8 program, six cycles for the construction of 64-point pseudopolarograms were measured automatically, one after the other, which lasted $16.5 \mathrm{~h}$ altogether. The results for the first and the sixth pseudopolarograms are given in Fig. 1. Comparing the curves of those two cycles of measurements, first to be noticed is a certain peak-height enhancement (Fig. 1A) as well as a complete peak potential shift and a slight peak broadening (Fig. 1B) occurred during the time elapsed. There are many propositions in the literature for the observed shift, and it could be ascribed to the contamination with organic material [9]. To avoid that, or to diminish at least, in the subsequent analyses a protocol based on cyclic voltammetry was established ( 20 cycles between -1.8 and $-0.1 \mathrm{~V}$ with the scan rate of $1 \mathrm{~V} / \mathrm{s}$ ) before a new pseudopolarogram, which proved helpful in "unblocking" the electrode. However, each peak-current pseudopolarogram was regular, with no gradient in the limiting current region for the first curve, showing no heterogeneous inert complexes present in the solution (only one-step pseudopolarogram) and, what was important to us, a stable behaviour of the solid electrode. The peak-position pseudopolarograms (Fig. 1B) shows an excursion of about $30 \mathrm{mV}$ in the positive direction when the deposition potential approached the half-wave potential of the redox reaction. This was also shown by Town and van Leeuwen [31] in the case of $\mathrm{Pb}(\mathrm{II})$ alone, and it is an indication that the filtered and acidified sample had no inert complexes present in the solution, at least not in the potential window of the method. The half-width of the peaks, as well as the shape of the single voltammograms, indicate simple and reversible electrode reaction (Fig. 1A inset). 

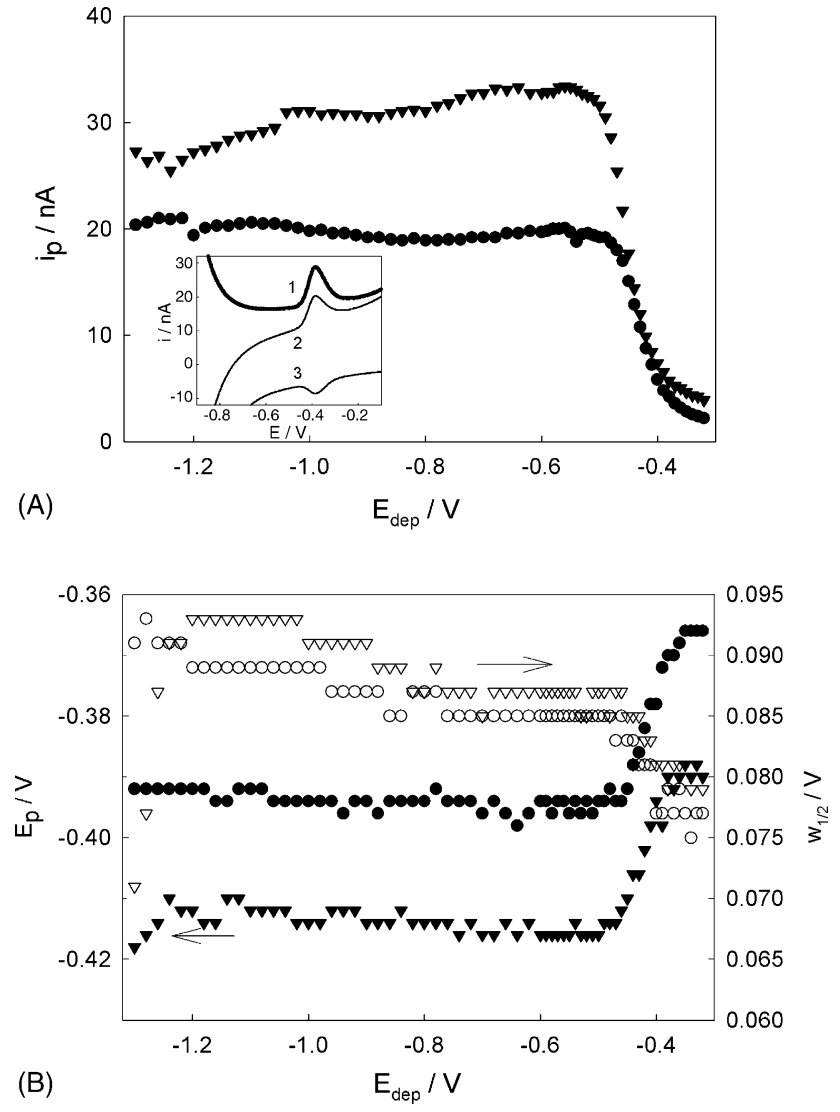

Fig. 1. Two series of 64-point pseudopolarograms in a filtered interstitial water sample of $\mathrm{pH} 2.13$ with $5 \times 10^{-6} \mathrm{~mol} \mathrm{~L}^{-1}$ of added lead (II). (•), first and ( $\boldsymbol{\nabla})$ sixth pseudopolarogram, respectively. (A) Peak-height vs. deposition potential; (B) peak-position and half-peak width vs. deposition potential; inset of A: a single SW voltammogram measured at $E_{\mathrm{dep}}=-0.430 \mathrm{~V}$. (1) Net current, (2) forward current, (3) backward current.

\subsection{Non-filtered interstitial water sample}

The following experiment witnesses the instability of the interstitial water sample despite the precautions taken according to the protocol, as well as its promptitude for changes. Interstitial water, freshly prepared under nitrogen atmosphere was transferred to the voltammetric cell. A few first SWV measurements showed a peak at about $-0.6 \mathrm{~V}$, which disappeared shortly afterwards. (The same reaction will be more stable in the sediment). Applying cyclic voltammetry, cleaning the electrode at $-2 \mathrm{~V}$ or washing with distilled water did not help with the reappearance of the peak. After lowering the $\mathrm{pH}$ from 8.60 to 4.07 with the addition of $\mathrm{HNO}_{3}$, which induced certain redistribution of species, the peak appeared again. Three pseudopolarograms were recorded, each of them constructed from 38 voltammograms. The $\mathrm{pH}$ of the solution after the first pseudopolarogram rose to 4.90, and after the third one the $\mathrm{pH}$ obtained was 5.86, which could be ascribed to the buffering capacity of the non-filtered water sample. The first pseudopolarogram is presented in Fig. 2. In Fig. 2A interesting peak-current and peak-area pseudopolarograms are presented which decline from the theoretically ideal shapes. The peak-position and the half-width versus the deposition potential curves are presented in Fig. 2B. A three dimensional (3D) presentation of all 38 square wave voltammograms is given in Fig. 2C. Partially similar cases were described in the literature $[27,21,31,47]$ however with better defined model solutions. Current decay at the very negative deposition potentials has not been reported yet, to the best of our knowledge. It was present in all the following cases at different degrees. Current decay might be connected with hydrogen evolution combined with some other source of perturbation on the electrode surface, while in the case of filtered interstitial water sample shown in Fig. 1, where $\mathrm{pH}$ was 2.13, such behaviour was not present. This might be due to the blocking of electrode by natural organic matter present in the solution with potential dependent surface-active qualities [48 p. 299]. The peak shift for the entire pseudopolarogram reads ca. $180 \mathrm{mV}$ and its direction is towards the more negative values as the deposition potential advances towards the more positive values. Similar behaviour was ascribed to the effect of ligand concentration at the electrode surface $[27,31,47,49]$.

When the $\mathrm{pH}$ of the same solution was lowered to 2.13 with the addition of $\mathrm{HNO}_{3}$ as in the case of filtered interstitial water sample, a peak at $-0.6 \mathrm{~V}$ disappeared, but another peak at $-0.33 \mathrm{~V}$ appeared, irregular in shape, i.e. double, but reversible. Finally, $6.3 \times 10^{-6} \mathrm{M} \mathrm{Pb}$ (II) was added to the solution. After a few single measurements and $3 \mathrm{~h}$ of equilibration when it was clear that the "free" lead was prevalent and when it was well checked that the cleaning period at $-0.1 \mathrm{~V}$ for $60 \mathrm{~s}$ is sufficient for avoiding memory effects, a new four series of pseudopolarograms were measured. The second pseudopolarogram is presented in Fig. 3. The pseudopolarogram looks like those of the filtered interstitial water by the general shape of peak current, potential and half-width. However, a step at about $-0.5 \mathrm{~V}$ indicating a non-labile complex is present in the peak current versus deposition potential curve (Fig. 3A). The peak potential vs. deposition potential curve has a more complex but reproducible shape in all four repetitions. It should be noticed that the peak potential shifts towards the more negative values in the region of inert complex reoxidation, as in the case of interstitial water at natural pH shown in Fig. 2, and it shifts towards the more positive values in the region of free lead reoxidation, which was the case with the behaviour of lead in filtered solution (Fig. 1B).

\subsection{Sediment}

The following measurements were performed in the sediment, prepared as described previously in Section 2. The reference and the counter electrodes were put into the sediment and the microelectrode was positioned with a micromanipulator. The depth profiles were not the subject of this presentation, but the signal considerably changed with the depth, dependent on the concentration of oxygen, and also with the position inside the sediment. Certain unhomogeneity was observed, so the authors incline to the theory of the existence of micro-niches with different characteristics, 

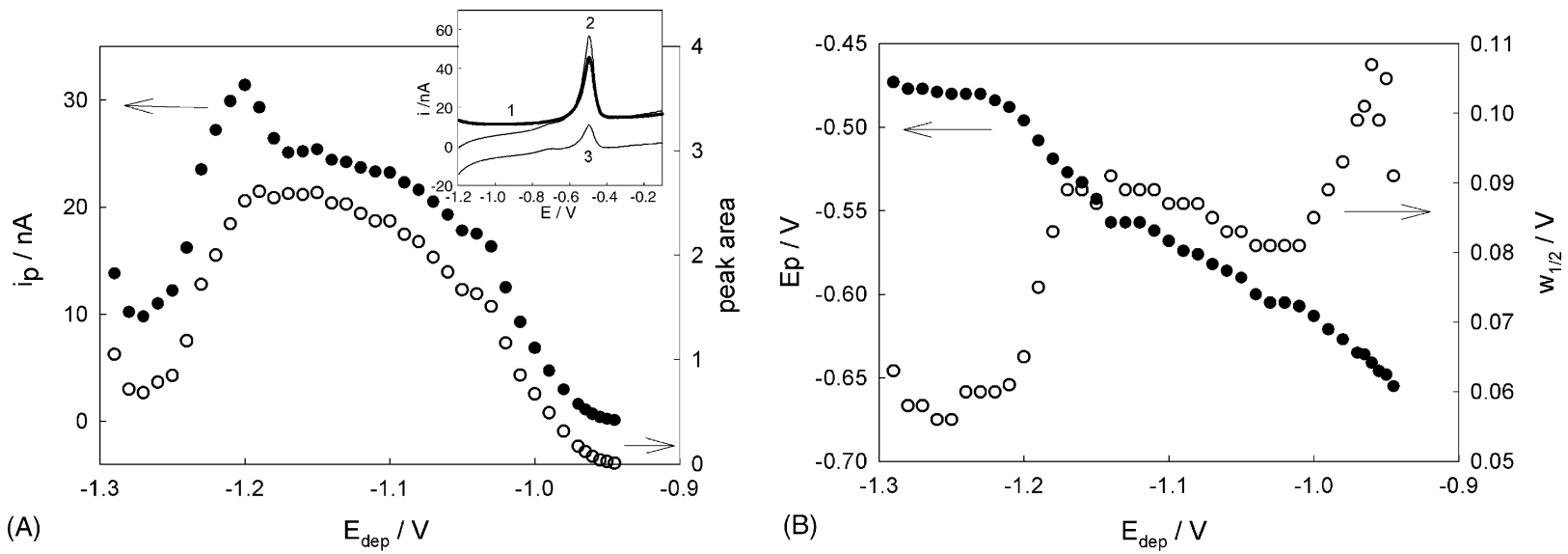

(A)

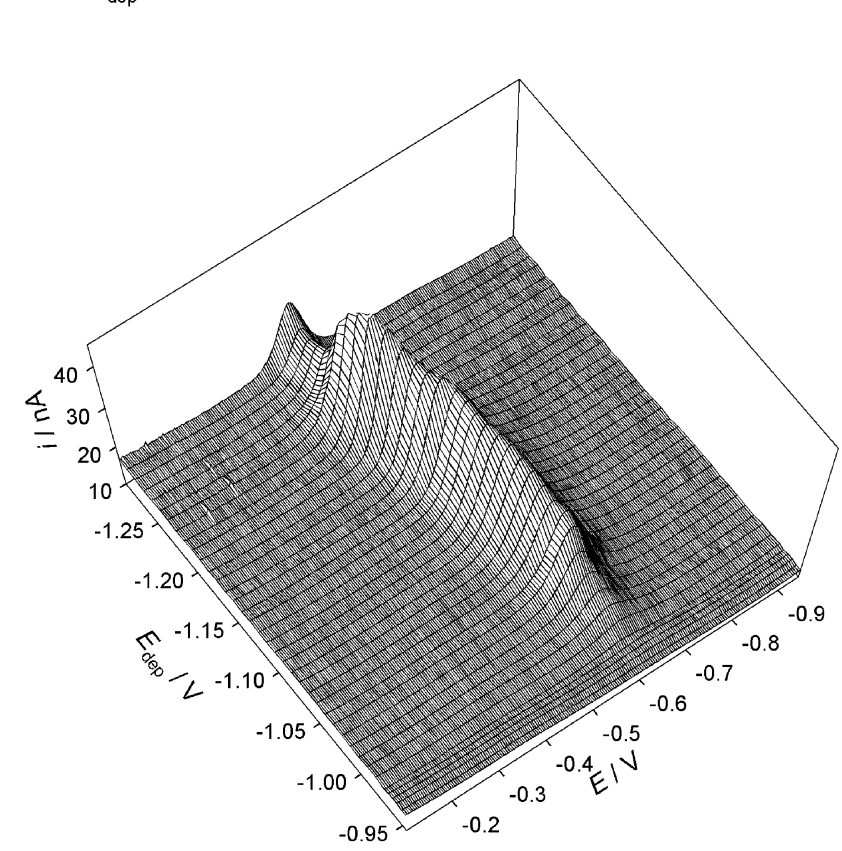

(C)

Fig. 2. A 38-point pseudopolarogram of a non-filtered interstitial water sample of $\mathrm{pH}$ 4.9. (A) Peak-height and peak-area vs. deposition potential; (B) peakposition and half-peak width vs. deposition potential; (C) 3D presentation of $38 \mathrm{SW}$ voltammograms used for the construction of pseudopolarograms in (A) and (B); inset of (A): a single SW voltammogram measured at $E_{\mathrm{dep}}=-1.200 \mathrm{~V}$. (1) Net current, (2) forward current, (3) backward current.

noticed as well by using the DGT and DET techniques [50]. There were positions where only one reversible peak was found at $-0.441 \mathrm{~V}$, the position where two peaks were simultaneously present, one more negative and irreversible at $-0.595 \mathrm{~V}$ and one more positive and more reversible at $-0.444 \mathrm{~V}$. At the position where high response of the more negative peak was found (this peak was huge in comparison with the more positive one), the entire pseudopolarographic measurement, with in-between $\mathrm{CV}$ cycles to unblock the electrode, was performed several times. Here, we are especially aware of the heterogeneous nature of the ligands, their possible adsorption on the electrode, and even the uncertainty of the reactant. From other analyses it was known about an increased concentration of lead in the interstitial water, even a few orders of magnitude larger than in the total sediment [46], so the working hypothesis of this experiment was that under the anoxic conditions that we reach with the solid microelectrode, we "see" the part of the dissolved lead inertly complexed with the ligands around, which rapidly changes its speciation when exposed to oxygen and/or low $\mathrm{pH}$ values.

One series of the resultant pseudopolarograms are shown in Fig. 4. presenting peak-height, peak-area, peak-position and half-peak width versus deposition potential. The shape of the $I_{\mathrm{p}}$ versus $E_{\mathrm{dep}}$ is again different with the expressed maximum before the decay of the current. The insight to the individual voltammograms clearly indicates the double nature of the peak implying the existence of different groups of ligands. The peak-potential behaved as in the case of charged interstitial water sample (Fig. 2) and showed an excursion of about $130 \mathrm{mV}$ in the negative direction as the deposition potential became more positive. This shows to the existence of low concentration of strong complexing ligands as explained earlier [27,21,31,47]. 


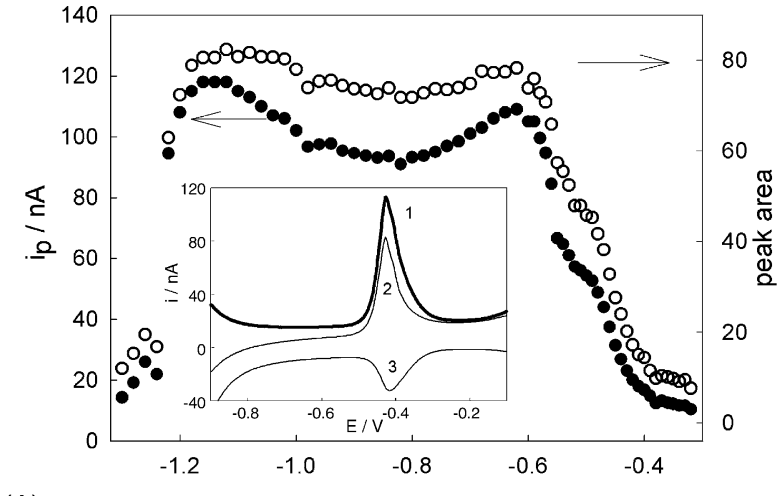

(A)

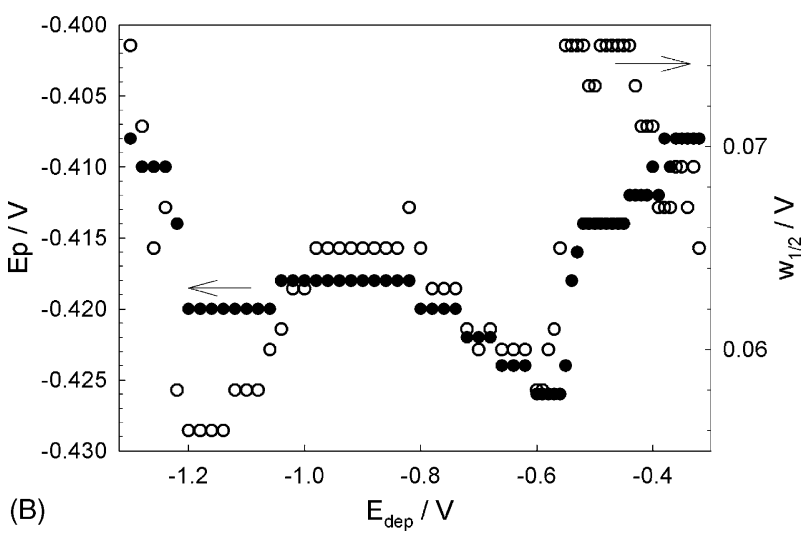

Fig. 3. A 64-point pseudopolarogram of a non-filtered interstitial water sample of $\mathrm{pH} 2.13$ with $6.3 \times 10^{-6} \mathrm{~mol} \mathrm{~L}^{-1}$ of added lead (II). (A) Peak-height and peak-area vs. deposition potential; (B) peak-position and half-peak width vs. deposition potential; inset of A: a single SW voltammogram measured at $E_{\text {dep }}=-0.570 \mathrm{~V}$. (1) Net current, (2) forward current, (3) backward current.

\subsection{Analyses of the signals}

The "so-called" logarithmic analysis of the currentvoltage $(i-E)$ curve [48 p. 129], in our case pseudopolarograms from Figs. 1-4, given by the expression: $\log \left(i_{\mathrm{d}}-\right.$ $i / i)=\alpha n F / R T\left(E-E_{1 / 2}\right)=\alpha n / 0.058\left(E-E_{1 / 2}\right)$, where $i_{\mathrm{d}}$ is limiting current, $\alpha$ is transfer coefficient, $n$ is number of electrons in the reaction, $F=96500 \mathrm{C}$, $R=8.314 \mathrm{~J} \mathrm{~mol}^{-1} \mathrm{~K}^{-1}, \quad T=293 \mathrm{~K}, \quad E_{1 / 2}$ is half wave potential, potential at which the value of $\log \left(i_{\mathrm{d}}-i\right) / i$ is zero, is shown in Fig. 5. The obtained half-wave potentials and the slopes of the linearized pseudopolarograms expressed in $\alpha n$ are summarized in Table 1. Besides the differences in the half-wave potential and the reversibility of the reactions, there is a remarkable difference $\left(\Delta E=E_{\mathrm{p}}-E_{1 / 2 \mathrm{pse}}\right)$ in the distances of the peak potentials $\left(E_{\mathrm{p}}\right)$ and the half-wave potentials $\left(E_{1 / 2 \mathrm{pse}}\right)$ of the pseudopolarograms, which is shown in Fig. 6. This shows to the existence of stronger complexes in the non-filtered interstitial water of higher $\mathrm{pH}$ ( $2 \mathrm{a}$ and $2 \mathrm{~b}$ ) and in sediment (4) than those in the filtered interstitial water of lower $\mathrm{pH}(1,3 \mathrm{a}$ and $3 \mathrm{~b})$. This also indicates to the existence of complexes prompt to changes during sampling and off-situ measurements.
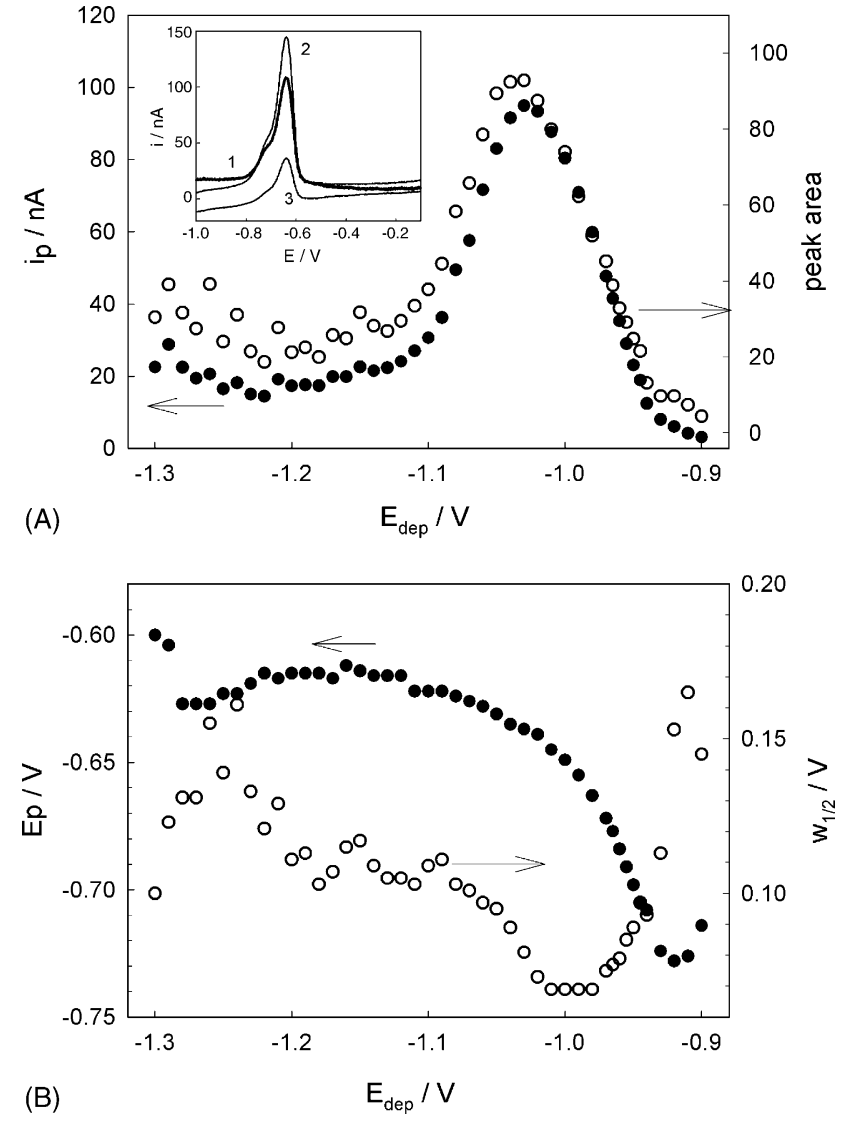

Fig. 4. A 44-point pseudopolarogram of a sediment measured in situ. (A) Peak-height and peak-area vs. deposition potential; (B) peak-position and half-peak width vs. deposition potential; inset of A: a single SW voltammogram measured at $E_{\mathrm{dep}}=-1.020 \mathrm{~V}$. (1) Net current, (2) forward current, (3) backward current.

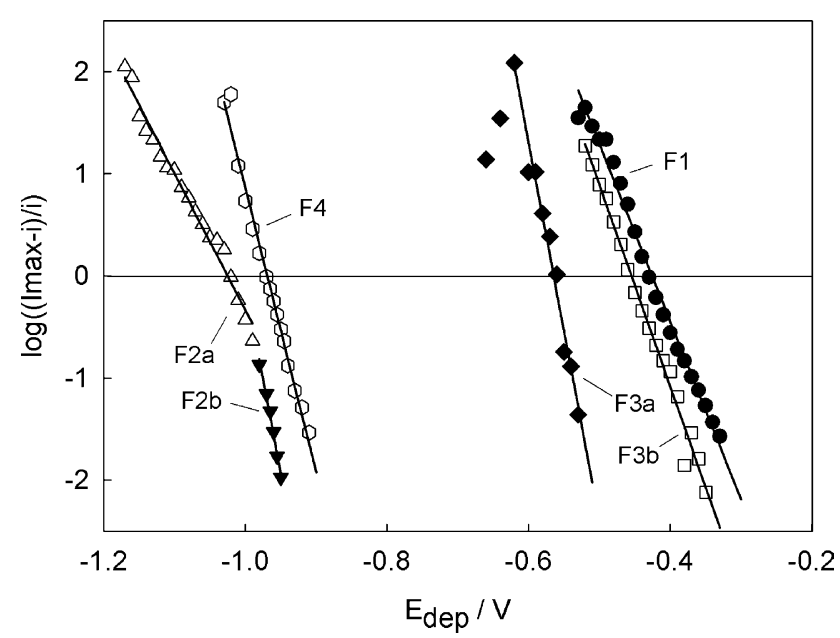

Fig. 5. Log analysis of pseudopolarographic curves shown in Figs. 1-4 vs. deposition potential. Numbers correspond to figures; (A) and (B) correspond to two slopes of one pseudopolarogram. The obtained half wave potentials and $\alpha n$ values from the slopes are given in Table 1. 
Table 1

Half-wave potentials and $\alpha n$ values from the logarithmic analysis of pseudoploragrams from Figs. 1-4

\begin{tabular}{lll}
\hline & $E_{1 / 2} / V \pm \mathrm{CI}$ & $\alpha n \pm \mathrm{CI}$ \\
\hline$F 1$ & $-0.426 \pm 0.003$ & $1.026 \pm 0.051$ \\
$F 2 \mathrm{a}$ & $-1.025 \pm 0.005$ & $0.791 \pm 0.054$ \\
$F 2 \mathrm{~b}$ & $-1.002 \pm 0.006$ & $2.201 \pm 0.335$ \\
$F 3 \mathrm{a}$ & $-0.565 \pm 0.004$ & $2.182 \pm 0.291$ \\
$F 3 \mathrm{~b}$ & $-0.455 \pm 0.003$ & $1.167 \pm 0.066$ \\
$F 4$ & $-0.969 \pm 0.002$ & $1.646 \pm 0.109$ \\
\hline
\end{tabular}

$\mathrm{CI}=$ confidence interval for $95 \%$ confidence limits.

An inversion occurred as well. The peaks of the SW voltammograms in the sediment were more negative than the other peaks for each of the given deposition potentials (inset in Fig. 6, curve 4). However, the corresponding pseudopolarographic half-wave potential was more positive than in the case of the non-filtered interstitial water, thus the $\Delta E$ of this latter is more important (Fig. 6, curves $2 \mathrm{a}$ and $2 \mathrm{~b}$ compared to curve 4). This matches with the perception of higher solubility and mobility of the reactants in anoxic conditions found in the sediments.

The fact that the peak potentials of SW voltammograms of the four measured cases differ so much, besides variations within each pseudopolarogram, is an information about the complex structure of the matrix, causing the complication of the reaction with the preceding and the following reactions that implement the complex reaction schemes [44] in both, the accumulation (reduction) and the stripping (oxidation) step. It would be interesting to compare those peak potentials with e.g. the peak potentials of the measurements of Rozan et al. [29] where no such information was given and where it was presumed that the peaks were at the potential of the free metal oxidation. There are, however, manifold differences between our case and the case just mentioned (reactant concentration range, type of the electrode), so a direct comparison could not be possible.

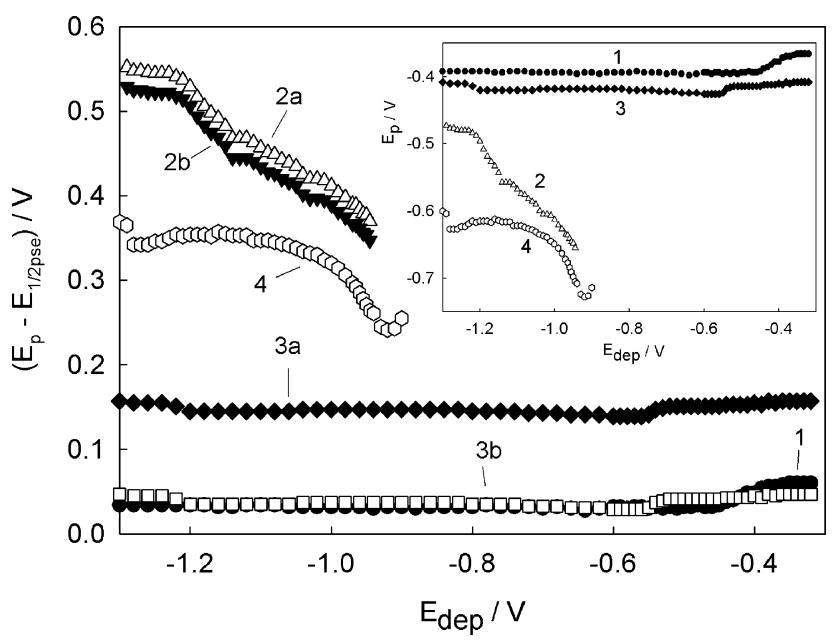

Fig. 6. Differences between the peak potentials and the half wave potentials of the pseudopolarograms obtained by log analysis shown in Fig. 5. Inset: dependences of peak potentials on deposition potentials for the pseudopolarograms shown in Figs. 1-4.
Making an estimation of thermodynamic stability constants based on the differences between half-wave potentials of the pseudopolarograms of free and inertly complexed reactant, like those given in the literature $[10,18,19,28,29]$ would be too uncertain, when the metal and the ligand side reactions are not known, as well as the half-wave potential of the uncomplexed reactant. At this stage we should acquiesce with witnessing and mapping the processes.

\section{Conclusion}

Microelectrodes that enable in situ measurements open new possibilities for detecting and characterizing metalligand complexes, especially those in anoxic conditions (very difficult to preserve during sampling), where the solubility of metal ions is significantly increased and their complexation with available ligands takes place. Pseudopolarography is a suitable method for the speciation - discerning between the free - labile and the inert metal complexes. Besides the peak-height versus deposition potential, the peak-area, the peak-position and the half-peak width versus deposition potential bear as well the information about the electrochemical processes, i.e. the characteristics of the species.

The results of measuring lead (II) in the sediment and its interstitial water characterize the sediment and also propose new challenges for modelling and simulating more complex reactions that occur in the so far rarely reachable conditions. Although the obtained pseudopolarograms differ from the theoretical ones, repeating of their shapes confirms the existence of useful information.

Our further work should concentrate on improving the sensor, i.e. the microelectrode, with respect of its sensitivity and stability, and on intensifying the fieldwork which should open new problematic and ideas to improve the measurement methods.

\section{Acknowledgements}

This research was supported by PNETOX and the Region Nord Pas-de-Calais [CPER and INTERREG (FrancoFlamand Programs)], as well as by COGITO, program of integrated actions by ÉGIDE. I.P. has benefited from the CNRS grant. The financial support of the Ministry of Science, Education and Sports of the Republic of Croatia (through the Grant No. 0098121) is gratefully acknowledged. We would like to thank two anonymous reviewers for their comments and suggestions.

\section{References}

[1] S. Bubić, M. Branica, Thalassia. Jugoslav. 9 (1973) 47.

[2] H.W. Nurnberg, P. Valenta, L. Mart, B. Raspor, L. Sipos, Z. Anal. Chem. 282 (1976) 357. 
[3] M. Branica, D.M. Novak, S. Bubić, Croat. Chem. Acta 49 (1977) 539.

[4] A. Zirino, S.P. Kounaves, Anal. Chem. 49 (1977) 56.

[5] D.R. Turner, M. Whitfield, J. Electroanal. Chem. 103 (1979) 43.

[6] D.R. Turner, M. Whitfield, J. Electroanal. Chem. 103 (1979) 61.

[7] M.S. Shuman, J.L. Cromer, Anal. Chem. 51 (1979) 1546.

[8] M. Lovrić, M. Branica, Croat. Chem. Acta 53 (1980) 485.

[9] S.P. Kounaves, Anal. Chem. 64 (1992) 2998.

[10] G. Branica, M. Lovrić, Electrochim. Acta 42 (1996) 1247.

[11] M. Lovrić, Electroanalysis 10 (1998) 1022.

[12] S.D. Brown, B.R. Kowalski, Anal. Chem. 51 (1979) 2133.

[13] S.P. Kounaves, A. Zirino, Anal. Chim. Acta 109 (1979) 327.

[14] A. Zirino, S.P. Kounaves, Anal. Chim. Acta 113 (1980) 79.

[15] L. Sipos, P. Valenta, H.W. Nurnberg, M. Branica, in: M. Branica, Z. Konrad (Eds.), Lead in the Marine Environment, Pergamon Press, Oxford, 1980.

[16] Š. Komorsky-Lovrić, M. Lovrić, M. Branica, J. Electroanal. Chem. 214 (1986) 37.

[17] Š. Komorsky-Lovrić, M. Branica, J. Electroanal. Chem. 226 (1987) 253.

[18] B.L. Lewis, G.W. Luther III, H. Lane, T.M. Church, Electroanalysis 7 (1995) 166.

[19] P. Croot, J.W. Moffet, G.W. Luther III, Mar. Chem. 67 (1999) 219.

[20] M. Vega, R. Pardo, M.M. Herguedas, E. Barrado, Y. Castrillejo, Anal. Chim. Acta 310 (1995) 131

[21] R.M. Town, M. Fillela, J. Electroanal. Chem. 488 (2000) 1.

[22] M. Branica, I. Pižeta, I. Marić, J. Electroanal. Chem. 214 (1986) 95.

[23] D. Omanović, M. Branica, Croat. Chem. Acta 71 (2) (1998) 421.

[24] C.L. Chakrabarti, J. Cheng, W.F. Lee, M.H. Back, W.H. Schroeder, Environ. Sci. Technol. 30 (4) (1996) 1245.

[25] R. Cleven, L. Fokkert, Anal. Chim. Acta 289 (1994) 215.

[26] Z. Lukaszewski, W. Zembrzuski, A. Piela, Anal. Chim. Acta 318 (1996) 159.

[27] J. Buffle, J.J. Vuilleumier, M.L. Tercier, N. Parthasarathy, Sci. Total Environ. 60 (1987) 75.

[28] G.W. Luther III, T.F. Rozan, A. Witter, B. Lewis, Geochem. Trans. 2 (2001) 65

[29] T.F. Rozan, G.W. Luther III, D. Ridge, S. Robinson, Environ. Sci. Technol. 37 (2003) 3845.

[30] H.P. van Leeuwen, R.M. Town, J. Electroanal. Chem. 536 (2002) 129.
[31] R.M. Town, H.P. van Leeuwen, J. Electroanal. Chem. 541 (2003) 51.

[32] H.P. van Leeuwen, R.M. Town, J. Electroanal. Chem. 561 (2004) 67.

[33] R.M. Town, H.P. van Leeuwen, J. Electroanal. Chem. 573 (2004) 147.

[34] D. Omanović, M. Branica, J. Electroanal. Chem. 543 (2003) 83.

[35] D. Omanović, M. Branica, J. Electroanal. Chem. 565 (2004) 37.

[36] D. Omanović, M. Lovrić, Electroanalysis 16 (2004) 563.

[37] W. Kaim, B. Schwederski, Bioinorganic Chemistry: Inorganic elements in the chemistry of life, John Wiley and Sons, Chichester, 1994.

[38] M.A. Huerta-Diaz, A. Tessier, R. Carignan, Appl. Geochem. 13 (1998) 213

[39] D.G. Cooper, J.W. Morse, Environ. Sci. Technol. 32 (1998) 1076.

[40] G.P. Kinkhammer, Earth Planet. Sci. Lett. 49 (1980) 81.

[41] T. Shaw, J.M. Gieskes, R.A. Jahnke, Geochem. Cosmochim. Acta 54 (1990) 1233.

[42] J. Hong, W. Calmano, U. Förstner, Interstitial waters, in: B. Salbu, E. Steinnes (Eds.), Trace Elements in Natural Waters, CRC Press, Boca Raton, 1995, pp. 117-150.

[43] G. Billon, B. Ouddane, J. Laureyns, A. Boughriet, Phys. Chem. Chem. Phys. 3 (2001) 3586.

[44] A.J. Bard, Z.R. Faulkner, Electrochemical Methods, Fundamentals and Applications, John Wiley and Sons Inc., New York, 2001, p. 471.

[45] I. Pižeta, G. Billon, J.-C. Fischer, M. Wartel, Electroanalysis 15 (2003) 1389.

[46] N. Vdović, G. Billon, C. Gabelle, J.-L. Potdevin, Environ. Pollut., in press.

[47] R.M. Town, H.P. van Leeuwen, J. Electroanal. Chem. 535 (2002) 11.

[48] J. Heyrovský, J. Kůta, Principles of Polarography, Publishing House of the Czechoslovak Academy of Science, Prague, Academic press, New York, 1966

[49] A.M.A. Mota, J. Buffle, S.P. Kounaves, M.L.S. Goncalves, Anal. Chim. Acta 172 (1985) 13.

[50] H. Zang, W. Davison, R.J.G. Mortimer, M.D. Krom, P.J. Hayes, I.M Davies, Sci. Total Environ. 296 (2002) 175. 